\title{
ESOFAGITE DE REFLUXO
} EM CRIANÇAS:

\section{estudo histológico e morfométrico}

\author{
Ana Maria A. A. MADER ${ }^{1}$, Maria Teresa de Seixas ALVES ${ }^{2}$, \\ Elisabete KAWAKAMI ${ }^{3}$ e Francy R. S. PATRÍCIO²
}

RESUMO - Racional - Refluxo gastroesofágico é afecção relativamente comum na infância e pode causar morbidade, havendo porém poucos estudos histológicos e morfométricos em biopsias esofágicas de crianças. Objetivo - Estudar aspectos histológicos e morfométricos da esofagite de refluxo em crianças. Material e Métodos - Foram analisadas 26 biopsias esofágicas (média de idade de 4,1 $\pm 3,4$ anos), com diagnóstico histológico prévio de esofagite de refluxo. Refluxo gastroesofágico também foi confirmado pela radiologia em 18, pHmetria em 5 e cintilografia em 3 pacientes. O sexo masculino predominou (84,6\%); vômitos pós-prandiais $(76,9 \%)$ e broncopneumonia de repetição foram os sintomas mais freqüentes. O grupo controle constou de sete crianças assintomáticas para refluxo gastroesofágico, cuja causa da morte foi meningococcemia (quatro casos) e cardiopatia congênita (três casos) (média de idade de 2,5 \pm 2,3 anos). Utilizaram-se as técnicas histoquímicas hematoxilinaeosina e ácido periódico de Schiff para avaliar infiltrado inflamatório, espessura do epitélio, da camada basal e o comprimento papilar. A morfometria foi feita por meio de sistema digital conectado ao software Pro-Image. Para análise estatística utilizouse o teste $t$ de Student, teste de Mann-Whitney, exato de Fisher e coeficiente de correlação de Pearson. Resultados - Espessura epitelial e da camada basal, comprimento papilar absoluto e relativo foram significativamente maiores no grupo de crianças com esofagite em relação ao grupo controle. Eosinófilos, neutrófilos e "balloon cells" não foram observados no grupo controle. Capilares intra-epiteliais foram observados em 11 casos de esofagite de refluxo (diâmetro médio de $59 \mu \mathrm{m}$ ), estando ausentes no grupo controle. Conclusão - Na esofagite de refluxo houve aumento da espessura epitelial, da camada basal, do comprimento papilar (em número absoluto e relativo) em relação ao controle. Houve, ainda, correlação linear positiva entre espessura epitelial total, espessura da camada basal e comprimento papilar, denotando maior "turnover" das células epiteliais. Polimorfonucleares eosinófilos, neutrófilos e "balloon cells" estavam presentes somente em biopsias de crianças com esofagite, sendo portanto, indicadores específicos desta afecção.

DESCRITORES - Esofagite péptica. Esôfago, patologia. Criança

\section{INTRODUÇÃO}

Refluxo gastroesofágico (RGE) é afecção relativamente comum na infância, podendo resultar em morbidade como esofagite, e doenças pulmonares, tais como pneumonias de repetição, broncoespasmo e episódios de apnéia ${ }^{(15,18,19)}$.

Os achados macroscópicos ou endoscópicos de esofagite consistem em hiperemia, friabilidade, erosões, ulcerações da mucosa e estenose do órgão. A forma erosiva, embora freqüente em adultos sintomáticos, está ausente em até $40 \%$ das crianças, sendo necessária a biopsia para confirmação diagnóstica e graduação da intensidade da esofagite, principalmente nas fases iniciais do processo inflamatório, quando o aspecto endoscópico pode ser quase normal ${ }^{(9)}$. A amostra geralmente é obtida por pinça endoscópica ou cápsula de sucção, sendo o fragmento obtido mais adequado, ou seja, mais profundo, quando retirado por cápsula ${ }^{(7,9,11)}$.

Em crianças, análises morfométricas randomizadas datam da década de 80, sendo os polimorfonucleares eosinófilos intraepiteliais considerados indicador sensível e precoce de esofagite de refluxo, estando a sua presença também relacionada à hiperplasia da camada basal epitelial e ao aumento do comprimento das papilas de lâmina própria. Por outro lado, polimorfonucleares neutrófilos tendem a surgir nos casos mais graves ${ }^{(1,8,13,20)}$.

\footnotetext{
Trabalho realizado no Departamento de Patologia da Universidade Federal de São Paulo - Escola Paulista de Medicina - UNIFESP-EPM, São Paulo, SP.

Departamento de Patologia da Faculdade de Medicina da Fundação ABC, Santo André, SP; ${ }^{2}$ Departamento de Patologia da UNIFESP-EPM; ${ }^{3}$ Disciplina de Gastroenterologia Pediátrica da UNIFESP-EPM, São Paulo, SP
}

Endereço para correspondência: Dra. Ana Maria A. A. Mader - Rua França Pinto, 832 - apto 41 - Vila Mariana - 04016-003 - São Paulo, SP. 
Em adultos com esofagite, a presença dos eosinófilos é a alteração mais freqüente em biopsias esofágicas ${ }^{(2)}$. No entanto, raros eosinófilos intra-epiteliais não devem ser valorizados como único critério para RGE, pois estes podem ocorrer na mucosa esofágica de indivíduos que fazem uso de álcool e/ou fumo ${ }^{(2,17)}$.

Dilatações vasculares numerosas e maiores do que $50 \mu \mathrm{m}$, leucoestase, diapedese e rupturas focais de vênulas de papilas alongadas, especialmente na superfície epitelial, também são valorizadas como indicador de esofagite de refluxo ${ }^{(3,7,12)}$. Células epiteliais pavimentosas balonizadas ("balloon cells"), com citoplasma abundante e pálido, núcleo irregular ou picnótico, geralmente ácido periódico de Schiff (PAS) negativos, não são específicas, podendo surgir em outras esofagites ${ }^{(10)}$. Células intra-epiteliais de contorno irregular (CINC ou "squiggle cell"), que em sua grande maioria correspondem à linfócitos $\mathrm{T}$, aumentam na esofagite de refluxo, também sem especificidade ${ }^{(4,5,14,19)}$.

\section{OBJETIVOS}

Estudar aspectos histológicos e morfométricos da esofagite de refluxo em crianças, comparando os achados obtidos com grupo controle.

\section{MATERIAL E MÉTODO}

Foram avaliadas retrospectivamente 26 biopsias de esôfago de crianças com idade igual ou menor do que 10 anos (média de 4,1 $\pm 3,4$ anos), com diagnóstico histológico de esofagite de refluxo, previamente estratificado em grau leve (I), moderado (II) e intenso (III), de modo subjetivo, levando-se em consideração o grau de hiperplasia da basal, do alongamento papilar e da densidade do infiltrado inflamatório intraepitelial. Estas biopsias foram selecionadas dentre 56 por apresentarem orientação adequada para análise morfométrica, ou seja, com epitélio representado na sua integridade, com pelo menos duas papilas de lâmina própria perpendiculares à lâmina basal epitelial, excluindo-se aquelas que continham epitélio de tipo colunar. Todas foram obtidas por pinça endoscópica de tamanho padrão, com abertura de $5 \mathrm{~mm}$, com aparelho endoscópico modelo pediátrico marca Pentax (modelo FG 24 X), 2 cm acima da transição esofagogástrica. Os achados endoscópicos foram previamente classificados em grau I (enantema), grau II (presença de erosões em terço distal que não atingem toda a circunferência do órgão) e grau III (erosões atingindo toda a circunferência do órgão).

Dados clínicos e exames complementares que corroborassem o RGE foram obtidos dos prontuários médicos. RGE foi detectado em 18 crianças pelo Rx contrastado do esôfago, estômago e duodeno (EED), em 5 pela pHmetria intra-esofágica prolongada e em 3 pela cintilografia; 4 apresentaram hérnia hiatal e 1 obstrução duodenal. O grupo controle constou de 7 crianças, com idade variando de 1 mês a 5 anos (média de 2,5 $\pm 2,3$ anos) necropsiadas no Serviço de Verificação de Óbitos da Capital de São Paulo, assintomáticas para RGE, sem internação hospitalar recente, 4 falecidas por meningococcemia e 3 por cardiopatia congênita. Os fragmentos foram retirados entre 2 e 3 $\mathrm{cm}$ da transição esofagogástrica .

Os espécimes foram submetidos a processamento histológico de rotina, com cortes de 5 a $6 \mu \mathrm{m}$ de espessura, corados pelas técnicas de hematoxilina-eosina (HE) e PAS, esta última para destacar melhor a camada basal.

\section{Morfometria}

As células inflamatórias intra-epiteliais (polimorfonucleares neutrófilos e eosinófilos) e "balloon cells", foram contadas em três campos de grande aumento (CGA-400X) com microscópio binocular, de objetivas acromáticas (Nikon Alphaphot YS). Estes três campos abrangiam a totalidade do material. No grupo controle, foram selecionados os três campos mais representativos. Para as medidas da espessura total epitelial e da camada basal, bem como do comprimento da papila de lâmina própria, utilizou-se o programa analisador de imagens equipado com o software Image-Pro Plus, versão 3.0 para Windows, da Media Cybernectis. As imagens foram obtidas com microscópio Olympus BX40 acoplado à câmara de vídeo Sony CCD-IRIS e transferidas para computador (Pentium $233 \mathrm{Mhz}$ ), com placa digitalizadora de imagem. As distâncias medidas foram determinadas utilizando-se o "mouse" para delinear as estruturas avaliadas. A análise foi feita em três campos de médio aumento (100X) e determinadas da seguinte forma: espessura do epitélio (distância da lâmina basal até a camada de queratinócitos mais superficial); espessura da camada basal (distância da lâmina basal até o nível da camada intermediária, onde os núcleos acham-se separados entre si por pelo menos um diâmetro nuclear); comprimento da papila (distância entre a lâmina basal inferior até a lâmina basal superior) e diâmetro dos capilares (maior distância entre uma célula endotelial até aquela diametralmente oposta). Os valores foram expressos em $\mu \mathrm{m}$. A partir destas variáveis, estabelecemos as relações: espessura da camada basal em relação ao epitélio e comprimento da papila (ambas numéricas de $0 \%$ a 100\%).

\section{Análise estatística}

Para a análise estatística, utilizou-se o teste $t$ de Student, exato de Fisher, de Mann-Whitney e coeficiente de correlação de Pearson, sendo considerados estatisticamente significantes os resultados, cujos níveis descritivos (valores de $P$ ) fossem inferiores a 0,05 .

\section{RESULTADOS}

No grupo de pacientes com esofagite de refluxo a idade variou de 3 meses a 10 anos, (média de 4,1 $\pm 3,4$ anos; $M=2,3$ anos), sendo 84,6\% do sexo masculino. No grupo controle, a idade variou de 1 mês a 5 anos (média de 2,5 $\pm 2,3$ anos; $\mathrm{M}=1$ ano), sendo $71,4 \%$ do sexo feminino. Os 
sintomas mais freqüentes do RGE foram vômitos (76,9\%), broncopneumonias de repetição $(37,5 \%)$, sibilos $(23,1 \%)$ e déficit neuropsicomotor $(23,1 \%)$.

O diagnóstico endoscópico foi de normalidade em 23,1\% dos casos, esofagite grau I em 38,5\%, grau II em 15,4\%, grau III em 3,8\% e presença de hérnia hiatal em $7,7 \%$.

Quanto ao diagnóstico histológico, observou-se esofagite grau I em $61,5 \%$, grau II em 34,6\% e grau III em 3,8\%. Quando comparados os diagnósticos endoscópicos e histológicos, observou-se discordância entre exame normal à endoscopia e esofagite grau I à histologia em $31 \%$ dos pacientes; índice de concordância de $58 \%$ em relação à esofagite grau I e de $50 \%$ em relação ao grau II e III (Tabela 1).

\section{Variáveis quantitativas e morfométricas}

Os valores da espessura epitelial, espessura da camada basal (número absoluto) e comprimento das papilas (número absoluto e percentual) foram significativamente maiores nas biopsias com esofagite em relação ao controle (Tabela 2).

As variáveis histológicas eosinófilos (Figura 1) (média: 5,3 $\pm 6,4$; $\mathrm{M}=2,7$ ), "balloon cells" (Figura 2) (média: 2,0 $\pm 1,4 ; \mathrm{M}=1,5$ ) e neutrófilos polimorfonucleares (média: $0,4 \pm 0,2 ; \mathrm{M}=0,0$ ) foram encontradas somente no grupo das esofagites, estando ausentes no grupo controle. Embora eosinófilos não tenham sido identificados em três casos de esofagite, estes apresentavam alterações epiteliais, ou seja, da camada basal e/ou papila.

Os capilares intra-epiteliais (Figura 3) estavam presentes em apenas 11 casos e seu diâmetro médio foi de 59,0 $\mu \mathrm{m}$ (desvio-padrão $=20,2 \mu \mathrm{m}$ ), sendo os valores mínimos e máximos de 35,4 $\mu \mathrm{m}$ e 103,7 $\mu \mathrm{m}$, respectivamente. Em 6 destes 11 casos, os diâmetros mediam acima de $50 \mu \mathrm{m}$.

Ao se considerar a espessura da camada basal como percentagem em relação à espessura do epitélio, observaram-se que em ambos os grupos a maioria $(70 \mathrm{a} 80 \%)$ ultrapassa os $15 \%$. Quanto à percentagem

TABELA 1 - Comparação entre os diagnósticos endoscópicos e histológicos

\begin{tabular}{lccc}
\hline \multicolumn{1}{c}{ Biopsia } \\
Endoscopia & Esofagite grau I & Esofagite grau II & Esofagite grau III \\
Normal & 5 & 1 & 0 \\
Esofagite grau I & 5 & 5 & 0 \\
Esofagite grau II & 2 & 2 & 0 \\
Esofagite grau III & 0 & 1 & 0 \\
Hérnia hiatal (HH) & 2 & 0 & 0 \\
HH + esofagite grau I & 2 & 0 & 0 \\
HH + esofagite grau III & 0 & 0 & 1 \\
\hline
\end{tabular}

TABELA 2 - Comparações entre as esofagites e o controle em relação às variáveis histológicas morfométricas

\begin{tabular}{lccc}
\hline & $\begin{array}{c}\text { Esofagite de refluxo } \\
\text { Média IC (95\%) }\end{array}$ & $\begin{array}{c}\text { Controle } \\
\text { Média IC (95\%) }\end{array}$ & Teste $\boldsymbol{t}$ de Student \\
\hline Espessura epitelial & 266,43 & 136,46 & $<0,001 *$ \\
Espessura da camada basal & $(236,94 ; 295,91)$ & $(103,77 ; 169,14)$ & $<, 001 *$ \\
& 55,81 & $(18,96 ; 34,81)$ & 46,49 \\
Comprimento da papila de & $(49,96 ; 61,66)$ & $(28,20 ; 64,77)$ & 20,13 \\
lâmina própria & 165,32 & $(14,34 ; 25,92)$ & 0,538 \\
Camada basal em relação ao & $(139,92 ; 190,72)$ & 32,94 & $(25,76 ; 40,11)$ \\
epitélio (\%) & 21,68 & $<0,001 *$ \\
Comprimento das papilas em & $(19,36 ; 24,02)$ & 61,53 & \\
relação ao epitélio(\%) & $(55,80 ; 67,26)$ &
\end{tabular}

IC = intervalo de confiança 


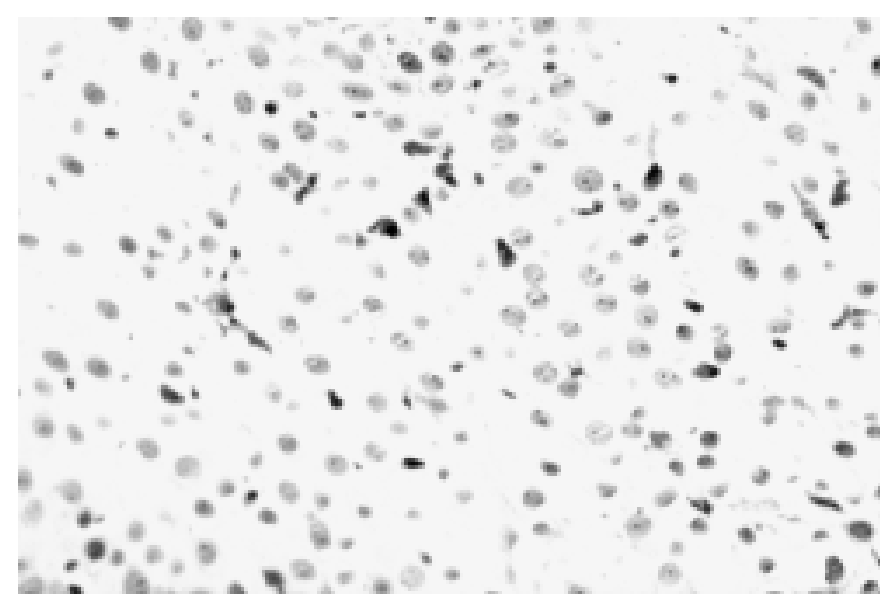

FIGURA 1 - Fotomicrografia hematoxilina-eosina (HE) 200X Esofagite de refluxo. Notam-se numerosos eosinófilos intra-epiteliais

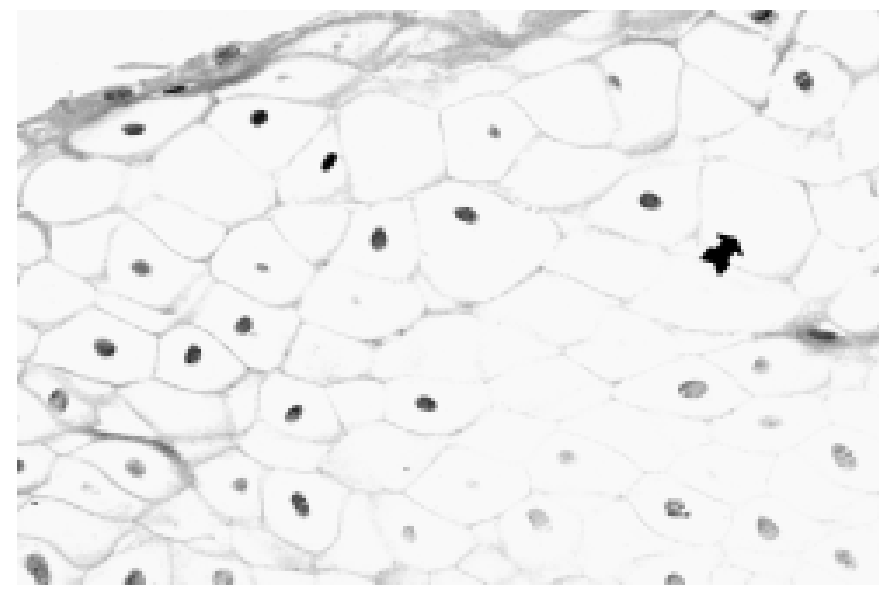

FIGURA 2 - Fotomicrografia hematoxilina-eosina (HE) 200X Esofagite de refluxo. Detalhe das "balloon cells" $(\vec{\rightarrow})$

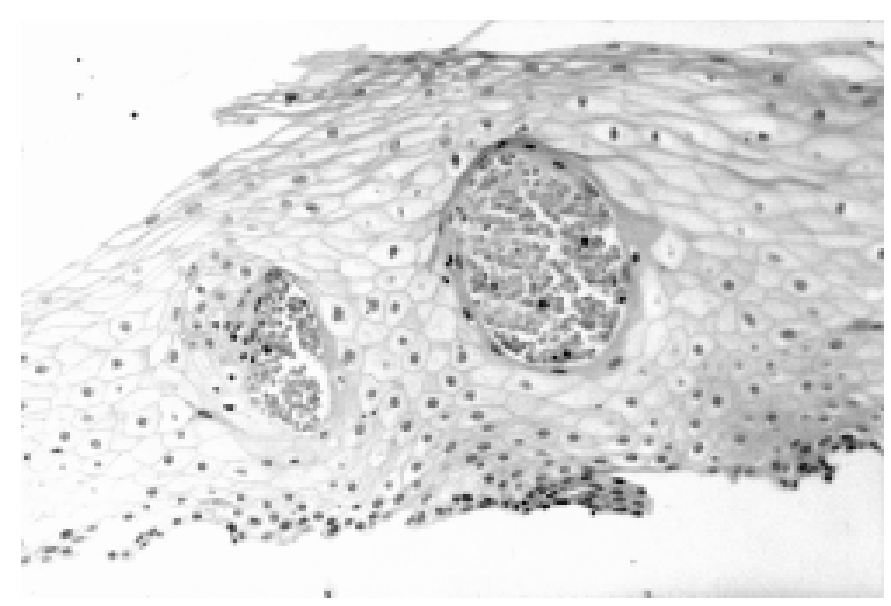

FIGURA 3 - Fotomicrografia hematoxilina-eosina (HE) 100X Esofagite de refluxo. Vênulas dilatadas próximas à superfície epitelial do comprimento das papilas, todos os que ultrapassaram $66 \%$ da espessura do epitélio pertenciam ao grupo das esofagites (Tabela 3 ).

Houve correlação linear positiva entre a espessura epitelial total e a espessura da camada basal $(P=0,032)$ e do comprimento papilar $(P<0,001)$, bem como entre estes dois últimos parâmetros $(P=0,005)$.

TABELA 3 - Comparações dos valores relativos da camada basal e papilas entre as biopsias de esofagite e grupo controle

\begin{tabular}{lccc}
\hline & \multicolumn{3}{c}{ Grupo } \\
\hline & $\begin{array}{c}\text { Esofagite de } \\
\text { refluxo n }(\%)\end{array}$ & Controle & $\begin{array}{r}\text { Teste exato } \\
\text { de Fisher }(P)\end{array}$ \\
$\begin{array}{l}\text { Espessura da camada } \\
\text { basal acima de 15\% }\end{array}$ & $23(88,5)$ & $5(71,4)$ & 0,282 \\
Comprimento das & $12(46,2)$ & 0 & $0,027^{*}$ \\
papilas acima de 66\% & & & \\
\hline
\end{tabular}

\section{DISCUSSÃO}

Biopsias realizadas por pinça endoscópica são consideradas relativamente superficiais, a maioria delas representadas apenas pelo epitélio de revestimento, o que não ocorre com aquelas obtidas por sucção ${ }^{(6,}$ 9). Orientação inadequada tem sido um problema relevante para análises morfométricas, com índices de inadequação de $86 \%$, fato observado no material desta série, no qual o índice de inadequação atingiu $46 \%{ }^{(2)}$.

Tratando-se de estudo retrospectivo, escolheram-se crianças abaixo de 10 anos de idade, tentando excluir possíveis efeitos do álcool e fumo, relacionados à presença de eosinófilos no epitélio esofágico ${ }^{(2,20)}$.

O grupo controle, proveniente de crianças assintomáticas para RGE e falecidas em curto espaço de tempo, é semelhante a grupos controles utilizados por outros autores em estudos morfométricos ${ }^{(1,16)}$.

Análise morfométrica computadorizada tem sido cada vez mais utilizada em substituição àquelas feitas com ocular micrometrada ${ }^{(5)}$, com vantagens em relação à rapidez e precisão do método.

Os sintomas mais freqüentes foram vômitos e pneumonias de repetição, similares a dados já relatados na literatura, bem como a idade média de $4,1 \operatorname{anos}^{(20)}$.

A concordância entre os diagnósticos endoscópicos e histológicos tende a ser maior nos casos mais acentuados da doença e menor nos graus I/II, sendo que algumas crianças com esofagite leve podem apresentar exame normal à endoscopia ${ }^{(9)}$. Consoante com este dado, $31 \%$ dos pacientes com esofagite grau I apresentavam exame normal à endoscopia; a concordância para o grau I e II foi de 58\% e 50\%, respectivamente. A presença de apenas um caso de esofagite grau III na presente casuística, talvez tenha dificultado a comparação entre achados endoscópicos e histológicos nas formas mais acentuadas da doença. 
A espessura média do epitélio foi de $266,43 \mu \mathrm{m}$, com diferença significativa em relação ao controle; alguns estudos pediátricos relatam espessura de $229 \mu \mathrm{m}$ e $247 \mu \mathrm{m}$, no entanto, sem diferir significativamente do grupo controle. Encontraram-se diferenças significativas para o comprimento das papilas tanto em número médio absoluto, como relativo em relação ao epitélio, quando se consideram como limite $50 \%$ e $66 \%(165,32 \mu \mathrm{m}$ e $61,53 \%)$, similar a valores relatados em outros estudos com crianças, ou seja, de 163,6 $\mu \mathrm{m}$ e 57,7 \%, sem no entanto diferir significativamente do controle ${ }^{(1,20)}$.

Em relação à espessura da camada basal, detectaram-se valores médios absolutos maiores, quando comparados ao grupo controle, ou seja, $55,81 \mu \mathrm{m}$ e $26,89 \mu \mathrm{m}$, respectivamente. No entanto, esta diferença deixa de ser significativa quando se comparam os grupos quanto aos valores relativos ao epitélio, ou seja, 21,68\% e 20,13\%, provavelmente porque o epitélio também ficou mais espesso. Por outro lado, o valor relativo da camada basal pode atingir até $39 \%$, com diferença significativa em relação ao controle, sem constatação de aumento expressivo da espessura epitelial total ${ }^{(1,20)}$.

Quanto aos capilares de papilas intra-epiteliais, estes estavam presentes em 11 casos de esofagite, sendo o diâmetro médio de $59 \mu \mathrm{m}$, portanto acima do valor de $50 \mu \mathrm{m}$, preconizado na literatura como indicador de refluxo ${ }^{(3)}$.

Polimorfonucleares eosinófilos ocorreram apenas nos casos de esofagite, em número que variou de uma a quatro células por CGA, variação que está contida nos dados da literatura que referem de 0,3 a 6,0 eosinófilos por $\mathrm{CGA}^{(5)}$; são extremamente raros ou ausentes no grupo controle e, portanto, considerados marcador específico e precoce de RGE. Por outro lado, polimorfonucleares neutrófilos tendem a surgir nos casos mais graves de esofagite ${ }^{(1,8,12)}$. "Balloon cells", embora não sendo sempre consideradas específicas de RGE, também somente foram identificadas nas esofagites, denotando o dano celular frente ao $\mathrm{RGE}^{(10)}$.

Houve ainda correlação linear positiva entre parâmetros morfométricos, tais como espessura epitelial total com a espessura da camada basal e com o comprimento papilar e entre estes dois últimos. Este dado evidencia a hiperplasia epitelial devido ao maior "turnover" celular, decorrente de crônica exposição da mucosa esofágica ao conteúdo gástrico ${ }^{(11)}$

Como conclusão, variáveis histológicas polimorfonucleares eosinófilos, neutrófilos e "balloon cells" são consideradas indicadores específicos da doença, pois apareceram somente nas esofagites, estando ausentes no controle. Ocorreu aumento da espessura epitelial total, da camada basal (valor absoluto) e do comprimento papilar (valor absoluto e relativo) em relação ao grupo controle. Houve correlação linear positiva entre a espessura epitelial, o comprimento das papilas e a espessura da camada basal epitelial, denotando maior "turnover" das células epiteliais esofágicas frente a sua exposição ao conteúdo gástrico.

Mader AMAA, Alves MTS, Kawakami E, Patrício FRS. Reflux esophagitis in children: histological and morphometric study. Arq Gastroenterol 2002;39(2):126-131.

ABSTRACT - Background - Gastroesophageal reflux disease is a frequent cause of morbidity in childhood, including esophagitis and recurrent respiratory symptoms; however histological and morphometric studies in esophageal biopsies of children are scarce. Aim - To study histological and morphometric findings in children with reflux esophagitis. Patients and Methods - We studied 26 esophageal biopsies of children (mean age: 4.1 years \pm 3.4 ) with reflux esophagitis, which prevailed in boys $(84.6 \%)$; post-prandial vomiting $(76.9 \%)$ and repetitive bronchopneumonia (38.5\%) were the most frequent symptoms. The diagnosis was made by X-ray in 18, by pH evaluation in 5 and by scintilography in 3 patients. The control group was formed by seven children without reflux symptoms who died from meningococcemia or congenital heart malformation (mean age: 2.5 years \pm 2.3 ). Histological variables were studied by hematoxylin-eosin and periodic acid of Schiff stain, inflammatory infiltrate, epithelial and basal layer thickness, papillary length and its ratio with the thickness of the epithelium. Morphometry was performed at a digital system connected to pro-image software. Student's $t$ test, Mann-Whitney test, Fisher and Pearson's correlation methods were used for the statistical analysis. Results - Epithelial and basal zone thickness, papillary length and its rate with thickness of epithelium, among the reflux group patients were higher than the control group. Eosinophils, neutrophils and "balloon cells" were not observed in the control group. Intraepithelial capillaries occurred in 11 cases in the reflux group (mean diameter: $59 \mu \mathrm{m}$ ). Conclusion - Epithelial and basal zone thickness, papillary length and its ratio with thickness of epithelium, resulted greater in the gastroesophageal reflux group than in the control group. There was a direct correlation between thickness of epithelium, basal zone thickness and papillary length, showing increased epithelial cell turnover. Eosinophils, neutrophils and "balloon cells" were observed only in patients with gastroesophageal reflux, thus serving as specific markers of this disease.

HEADINGS - Esophagitis, peptic. Esophagus, pathology. Child. 


\section{REFERÊNCIAS BIBLIOGRÁFICAS}

1. Black DD, Haggitt RC, Orenstein SR, Whitington PF. Morphometric histological diagnosis and correlation with measures of gastroesophageal reflux. Gastroenterology 1990;98:408-14.

2. Brown FL, Goldman H, Antonioli DA. Intraepithelial eosinophils in endoscopic biopsies of adults with reflux esophagitis. Am J Surg Pathol 1984;8:899-905.

3. Collins BJ, Elliott H, Sloan JM, McFarland RJ, Love AHG. Oesophageal histology in reflux oesophagitis. J Clin Pathol 1985;38:1265-72.

4. Cucchiara S, D'Armiento F, Alfieri E, Insabato L, Minella R, Magistris TM, Scoppa A. Intraepithelial cells with irregular nuclear contours as a marker of esophagitis in children with gastroesophageal reflux disease. Dig Dis Sci 1995;40:2305-11.

5. Digiorggio JC, Orenstein SR, Shalaby TM, Mahoney TM, Wisniewski SR, Becich MJ. Quantitative computer-assisted image analysis of suction biopsy in pediatric gastroesophageal reflux. Pediatr Pathol 1994;14:653-64

6. Frierson HF. Histology in the diagnosis of reflux esophagitis. Gastroenterol Clin North Am 1990;19:631-43.

7. Geboes K, Haot J, Mebis J, Desmet VJ. The histopathology of reflux esophagitis. Acta Chir Belg 1983;83:444-8.

8. Goldman H, Antonioli DA. Mucosal biopsy of the esophagus, stomach and proximal duodenum. Hum Pathol 1982;13:423-48.

9. Hyams JS, Ricci A, Leichtner AM. Clinical and laboratory correlates of esophagitis in young children. J Pediatr Gastroenterol Nutr 1988;7:52-6.

10. Jessurum J, Yardley JH, Giardiello FM, Hamilton SR. Intracytoplasmic plasma proteins in distended esophageal squamous cells (balloon cells). Mod Pathol 1988; $1: 175-81$.
11. Johnson LF, Demeester TR, Haggitt RC. Esophageal epithelial response to gastroesophageal reflux. A quantitative study. Am J Dig Dis 1978;23:498-509.

12. Kobayashi S, Kasugai T. Endoscopic and biopsy criteria for the diagnosis of esophagitis with a fibreoptic esophagoscope. Am J Dig Dis 1974;19:345-52.

13. Leape LL, Bhan I, Ramenofsky ML. Esophageal biopsy in the diagnosis of reflux esophagitis. J Pediatr Surg 1981;16:379-84.

14. Mangano M, Wang H, Schnitt S, Antonioli D. Nature e significance of cells with irregular nuclear contours (CINC) in esophageal mucosal. Lab Invest 1991;64:387.

15. Orenstein SR, Izadnia F, Khan S. Gastroesophageal reflux disease in children. Gastroenterol Clin North Am 1999;28:947-69.

16. Shub MD, Ulshen MH, Hargrove CB, Siegal GP, Groben PA, Askin FB Esophagitis: a frequent consequense of gastroesophageal reflux in infancy. J Pediatr 1985;107:881-84

17. Tummala V, Barwick KW, Sontag SJ, Vlahcevic R, Mc Callum RW. Significance of intraepithelial eosinophils in the histologic diagnosis of gastroesophageal reflux. Am J Clin Pathol 1987;87:43-8.

18. Vandenplas Y. Reflux esophagitis in infants and children: a report from the Working Group on Gastro-Oesophageal Reflux Disease of the European Society of Paediatric Gastroenterology and Nutrition. J Pediatr Gastroenterol Nutr 1994;18:413-22.

19. Wang HH, Mangano MM, Antonioli DA. Evaluation of lymphocytes in esophageal mucosal biopsies. Mod Pathol 1994;7:55-8.

20. Winter HS, Madara JL, Stafford RJ, Grand RJ, Quinlan JE, Goldman H Intraepithelial eosinophils: a new diagnostic criterion for reflux esophagitis. Gastroenterology 1982;83:818-23.

Recebido em 30/7/2001 Aprovado em 14/1/2002 